\title{
The academic performance of students
} with a migrant background: evidence from a cohort enrolled at Sapienza University of Rome

\author{
Cristina Giudici ${ }^{*} \mathbb{0}$, Eleonora Trappolini ${ }^{2}$ and Donatella Vicari ${ }^{3}$
}

\author{
*Correspondence: \\ cristina.giudici@uniroma1.it \\ ${ }^{1}$ Dipartimento di Metodi \\ e Modelli per l'Economia, \\ il Territorio e la Finanza, \\ Sapienza Università di Roma, \\ Rome, Italy \\ Full list of author information \\ is available at the end of the \\ article
}

\begin{abstract}
This study investigates the demographic characteristics and academic performances of foreign students with an Italian educational background in a cohort of 1st-year Bachelor students enrolled at Sapienza University of Rome, in the a.y. 2012/2013, comparing them to Italian and to International students. First, we employed a discrete-time competing risk hazard model to analyse differences in academic performances between Italian, foreign students with an Italian educational background and foreign students with a foreign educational background. Second, we applied regression trees to investigate final grades and the time-to-degree completion of Bachelor's degree holders. Results show differences in the academic performances of foreign students with an Italian educational background compared to Italian students. Policies are needed, these results suggest, that strengthen opportunities for students from a migrant background since high school.
\end{abstract}

Keywords: University, Academic success, Foreign students, Educational background, Competing risk hazard model, CART

\section{Background}

Foreign students in higher education have been much written about in the international literature. There has been a focus on both: the internationalisation policies of tertiary education institutions (OECD, 2019); and the integration of foreign students within an academic context (Marmolejo et al., 2008). At the international level, a consolidated literature distinguishes: degree-mobile students, i.e. people moving to a country for studies; from children of immigrants who enrol in a university.

Degree-mobile students have to be framed in the context of international degree mobility and are generally assumed to be people accessing university programmes with a prior foreign diploma, which would formally entitle the student to enrol. In the literature, they are defined as international students. This kind of mobility has been driven by a variety of push-and-pull factors. For instance, there is the growing demand for tertiary author(s) and the source, provide a link to the Creative Commons licence, and indicate if changes were made. The images or other third party material in this article are included in the article's Creative Commons licence, unless indicated otherwise in a credit line to the material. If material is not included in the article's Creative Commons licence and your intended use is not permitted by statutory regulation or exceeds the permitted use, you will need to obtain permission directly from the copyright holder. To view a copy of this licence, visit http:// creativecommons.org/licenses/by/4.0/. 
education in countries with low education, that leads students to look for educational opportunities abroad, or for job prospects after graduation.

The children of immigrants are increasingly studied in countries with a long history of migration. In these countries, the integration process has seen a growing share of second and third generation immigrants in higher education.

Several definitions are used in the literature to identify the various generations of the children of immigrants: following Rumbaut (1997) the distinction between the first and second generation could be based on the place of birth and the age of arrival. Those born in the newly adopted country or who arrived at pre-primary school age belong to the second generation stricto sensu. Those who arrived at school age may be regarded as being at a midpoint between their parents and the host society. These students are often defined as "generation 1.5".

In the literature on school achievement, the two groups-second generation and generation 1.5-are often considered together as being de facto second generation, independently of where they were born. Thus, hereafter we refer to pupils of foreign origin in school as "second generation students".

The share of international and second-generation students within the academy depends on the migration history of the country and the level of immigrant integration in the country. In countries with a long history of immigration, second-generation students are numerous. Nonetheless, if national regulation on citizenship acquisition follows the principle of ius soli, they will not be statistically visible. At the other extreme, in countries of recent immigration where national regulation on citizenship acquisition follows the principle of ius sanguinis, second-generation migrants are likely to retain their parents' citizenship and to enter university as foreign students.

The academic performances of foreign students are of increasing interest in many European countries. Where tertiary education is publicly provided, governments regularly make decisions about support levels given to universities based on student performance and the efficiency of the system (Agasisti \& Salerno, 2007; Aina et al., 2011). It is also true that improving the participation and the graduation levels of migrants and their children in tertiary education has been recognised as a challenge for the education system of host countries (Marmolejo et al., 2008).

In Italy, a well-established literature on migration deals with the educational attainment of children of immigrants at school (Azzolini et al., 2019), while their access to tertiary education is an emerging issue. The few studies on Italian universities and migrants refer to the socio-economic and psychological aspects of entering university, while there is very little research on academic performance and graduation rates.

The aim of the study is to analyse the demographic characteristics and academic performances of foreign students with an Italian educational background belonging to a cohort of 1st-year Bachelor students enrolled at Sapienza University of Rome, in the a.y. 2012/2013. This cohort is compared with Italian and foreign students with a foreign educational background. Academic performances have been assessed in two steps. First, by applying a discrete-time competing risk hazard model, we examined differences in getting the Bachelor's degree, drop-out, and transfer rates between Italian, secondgeneration and international students. Second, focusing only on Bachelor's degree holders (from now on BAs), we analysed final grades and the time-to-degree completion by 
applying regression trees. While the time for completion measures the speed taken for the degree, the final grade is an important aspect of the performance because it is a quality indicator of the academic career of BAs.

\section{Literature background}

There is a large international literature on foreign students in tertiary education, dealing with either international or second-generation students. As for international students, the analysis of the relevant and vast literature is beyond the scope of this study. Nonetheless, we referred to the most significant results shared within the academic community. A common theme that is often recalled in the literature is the difficulty experienced by international students in adapting to a new academic context (Andrade, 2006; Andrade \& Evans, 2009; Norton \& Fatigante, 2018; Smith \& Khawaja, 2011). Language problems and alienation from the broader university community are among the most frequent problems that lead to the underperformance of international students with respect to nationals (Andrade, 2006; Andrade \& Evans, 2009; Sherry et al., 2010).

Looking at second-generation students, though the focus of the international debate on their educational attainment is mainly about secondary school, there is an important body of international migration literature in countries with a long immigration history (Collins \& Magnan, 2018; Feliciano \& Lanuza, 2017; Feliciano \& Rumbaut, 2005; Griga \& Hadjar, 2014; Heath \& Brinbaum, 2007; Heath et al., 2008; Marmolejo et al., 2008; Murdoch et al., 2014; Orupabo et al., 2020).

A finding that is well-established and that emerges from the international literature is the persistence of poor results in school performances and in the education levels achieved by the children of immigrants compared to their native peers (Bertozzi, 2018). An interesting insight is given by Heath et al. (2008), in their review of the educational attainment of second-generation minorities in Western Europe. The authors show that minorities from less-developed countries appear to be particularly disadvantaged in education. The disadvantages are often more evident earlier in the school career, but the authors detect differences according to countries of origin and ethnicity. Moreover, significant educational disadvantages remain in several countries, even after controlling for social background.

Gender issues have also risen in relation to educational success. More specifically, some scholars suggest that gender differences in education may be affected by the migration experience (Freudenthaler et al., 2008; Ravecca, 2010). Scholars explain such educational inequalities among second-generation students with reference to a number of personal and contextual factors, such as personal characteristics, social and economic status and the flexibility of secondary-school systems. For a review of influential factors in predicting students' academic success see Alyahyan and Düştegör (2020).

\section{Empirical evidence in Italy}

Italy has historically been a country of emigration, but, since the 1980s, it has gradually turned into a destination country. One of the consequences of this transformation has been, since 2000, the growing presence of children of immigrants in the Italian education system. 
In this context, second-generation students in tertiary education are an emerging issue within the Italian literature on migration. They are, after all, only now reaching university age in large numbers.

According to national statistics (MIUR, 2020), in the a.y. 2019/2020 almost 16,000 students with foreign citizenship enrolled in the Italian university (5.4\% of total enrolment). In the last decades, the structure of this population has been evolving, as a result of various push-and-pull factors, linked both to the internationalisation of Italian Higher Education, and to the migration history of the country: international students were the most numerous subgroup within universities, until a.y. 2011/2012, when they were overtaken by foreign students entering university with a diploma obtained in Italy. Nowadays, $45 \%$ of foreign students accessed the Italian university system with a diploma obtained abroad, while 55\% came out of Italian High Schools (MIUR, 2020).

An extensive literature has examined the student population as a whole, without distinguishing for migrant background, and has focused on different aspects of the academic path (Contini et al., 2018; Enea \& Attanasio, 2017; Garibaldi et al., 2012). Despite the growing focus on foreign students, especially in the field of psychological and sociological studies, there is a lack of quantitative studies on foreign students with an Italian education background.

\section{Foreign students with an Italian educational background: access to university and academic achievement}

Foreign pupils enrolled in Italian schools represent approximately $10 \%$ of all school students, from 180 different nationalities, 64\% of them were born in Italy (MIUR, 2020).

As Italian citizenship legislation (Law no. 91/1992) is based on ius sanguinis, children born in Italy to two foreign parents are considered foreign nationals, and can claim Italian citizenship only after uninterrupted legal residence in Italy up to the age of 18 . Foreign nationals who are born abroad may also become Italians after 10 years of legal residence in the country. This citizenship legislation is among the most restrictive in Europe, and even after conditions are met the bureaucratic process of attaining citizenship may take up to 3 years. This means that at the time of enrolling in university, the children of immigrants are likely to hold the citizenship of their parents. Only a small proportion will be naturalised.

Speaking generally, students' chances of enrolling at university are, in the Italian educational system, strongly associated with high-school track choices (Azzolini et al., 2019; Vergolini \& Vlach, 2017).

Among students who completed the high school track, the share of those enrolling in university in the same year is $74 \%$ for Lyceums (which last 5 years and provide a general, academic-oriented education), while the percentage drops to $33 \%$ and $11 \%$ for Technical or Vocational diploma, respectively (MIUR, 2017). With reference to students with foreign citizenship, Paba and Bertozzi (2017) show that secondary-school-graduates with migrant origin are less likely to enrol in university compared to their Italian peers. In their study on higher education beliefs and intentions among immigrant-origin students in Italy, Mantovani et al. (2018) suggest that immigrant-origin youths have weaker higher education intentions than Italian students. They show that this figure is largely due to prior decisions in favour of non-academic school tracks. Following the same line, 
Contini and Azzolini (2016) find that children of immigrants exhibit higher likelihood to opt for vocational training over more generalist and academic programmes. Using decomposition methods, the authors show that a large share of the immigrant-native differentials in the probability to attend the different school programmes is explained by the different prior performance distribution. Nonetheless, given social background and prior performance, children of immigrants still enrol in school careers that prevent them access to tertiary education. Interestingly, Paba and Bertozzi (2017) observed that university transition rates from Technical or Vocational diplomas are actually similar for national and foreign students. The authors stress that the main difference between the two groups is the high proportion of foreign students with a Lyceum diploma who do not continue their studies.

The access of children of immigrants to Italian universities has been also analysed by Bertozzi (2018) using a qualitative approach. The author highlights the importance of limited economic resources, limited social and cultural capital, type of high school diploma and information bias. All these, she suggests, limit students' opportunities. Analogously, in a qualitative study carried out at the University of Bologna, Bozzetti (2018) examines the challenges and the resources faced by young immigrants when they continue their university studies. The author stresses the central role of parents, both from an economic and an emotional point of view, and argues that the reasons that young people give up their studies is most frequently linked to the need to contribute to family life, rather than to any mistrust of the Italian educational system.

As regards academic success, the panorama of studies is underdeveloped. Nonetheless, some differences have increasingly attracted attention. Pioneering research conducted by Lagomarsino and Ravecca (2014) on university students in the city of Genoa flagged up the importance of social networks and secondary-school resources in facilitating both the access of students with foreign citizenship to tertiary education and their successful integration there.

Looking at the most recent data published by AlmaLaurea (2020), the share of graduates with foreign citizenship in Italian Universities has appreciably increased in the last decades, from $2.7 \%$ in 2007 to $3.7 \%$ in 2019 . Moreover, among foreign students, the share of those who come from Italian high schools rose from 28\% in 2011 to $42 \%$ in 2019. Over half of foreign graduates in 2019 come from Europe, in particular from Albania (11.4\%) and Romania (10.8\%).

Since there is no official limit to the number of years that a student can be enrolled in a programme of study, Bachelor's Degree takes, on average, longer than the prescribed duration of the programme (AlmaLaurea, 2018). Nonetheless, research in this field generally refers to the global population of tertiary students, and rarely distinguishes by migrant background. Indeed, when citizenship is included in the analysis, it is generally considered only as a control variable.

To the best of our knowledge, the only study that has been carried out in this field using a quantitative approach is the one by Aiello et al. (2020). In this work the authors analyse the national micro-data of students for three cohorts of 1st-years, 2011/2012, $2014 / 2015$ and $2017 / 2018$. They do so by looking at citizenship and country of educational background. The study clearly shows the disadvantage suffered by international students in terms of low success rates, but also the disadvantage of second-generation $v s$ 
Table 1 Profiles of students according to their citizenship and their country of prior education

\begin{tabular}{|c|c|c|}
\hline \multirow[t]{2}{*}{ Country of prior education } & \multicolumn{2}{|l|}{ Citizenship } \\
\hline & Italian & Foreign \\
\hline Italy & $\begin{array}{l}\text { Italian students with Italian educational } \\
\text { background }\end{array}$ & $\begin{array}{l}\text { Foreign students with } \\
\text { Italian educational } \\
\text { background (second } \\
\text { generations) }\end{array}$ \\
\hline Abroad & $\begin{array}{l}\text { Italian students with foreign educational } \\
\text { background }\end{array}$ & $\begin{array}{l}\text { Foreign students with } \\
\text { foreign educational } \\
\text { background (international } \\
\text { students) }\end{array}$ \\
\hline
\end{tabular}

national students. Although the authors observe that attending a high school in Italy is a significant advantage for foreign students, they also point out that second-generation students are characterised by higher propensity to drop out and lower Bachelors' degree rates.

In addition to delayed graduation rates, the final grade has also become part of the debate. According to AlmaLaurea (2020), during the last decade the average final grade has been broadly stable (103.1/110), and varies with the course of study pursued. Foreign students with an Italian high school diploma have higher final grades than international students (respectively, 99.1/110 vs 98.1/110) and lower final grades than Italian students $(104.2 / 110)$. Even if the final grade is interpreted as a measure of educational quality, several authors suggest that differences in grades from different study programmesdifferences that can sometimes be important-are not necessarily due to educational quality. On this basis, in order to adjust for potential bias, the relevant literature recommends taking into consideration the study programme when investigating academic performances (Mignoli, 2012).

\section{Definitions and research hypotheses}

By combining citizenship and country of prior education we identified four student profiles, which are shown in Table 1.

Within the group of foreign students, the Italian-educated group includes the children of immigrants who were born in Italy or arrived in the country at school age and have not been naturalised (the de facto second generation).

Those whose prior education was carried out abroad represent the population of international students stricto sensu. Therefore, from now on, we define International Students (ISs) as those foreign students with a foreign educational background, and second-generation students (SGs) as foreign students with an Italian educational background.

In order to frame our research in the light of the abovementioned literature, we can formulate three main research hypotheses.

Hypothesis 1 (H1) We expect foreign students will perform worse than Italian students in terms of BAs rates, time-to-degree and final grade. Nevertheless, we expect the gap between second-generation and Italian students to be smaller than the one between international and Italian students. 
Hypothesis 2 (H2) Women are expected to perform better than men in both national and foreign student populations, and the gender gap in educational achievement is expected to be particularly relevant among second-generation students.

Hypothesis 3 (H3) Finally, we expect foreign students from immigrant populations who are better integrated in the Italian social and cultural context, to do better in terms of performance.

\section{Data and methods}

Our study is based on the administrative data of Sapienza University of Rome, which is the largest University in Europe, with over 100,000 students. Sapienza has the largest number of foreign students in Italy (about 8000).

Data refers to 15,203 full-time students who enrolled for the first time in a 3-year Bachelor's degree in the a.y. 2012/2013". ${ }^{1}$ Regardless of the actual administrative enrolment date, we conventionally set the initial date of the degree for each student to 1 st October 2012. We did so because this date generally represents the beginning of the semester, when students can start to attend classes: administrative registration is often completed several months later.

According to the approach adopted by OECD (2019), we followed the cohort for twice the duration of the study programme, i.e. $3+3$ years, with three additional months in order to include students who get the BA degree within the end of the solar year (31st December). Thus, the time of the follow-up is 75 months.

Student demographic characteristics include age at enrolment, gender, geographical area of citizenship (Italy; Romania; Eastern Europe; Africa; Asia; Latin America; Western countries), and place of domicile at enrolment (Rome; out of Rome). Academic characteristics include type of High-school diploma (Classical and Scientific Lyceum; Other Lyceum; Technical or Vocational High school; Foreign High school), disciplinary area (Architecture; Economics; Humanities; Social Sciences; Engineering, Informatics and Statistics; Healthcare professions and Psychology; Scientific disciplines); scholarship, date of the BA degree, and final grade. In addition to the latter characteristics, there is also a dummy variable that also provides information on the country (Italy/abroad) where the student obtained his or her prior education, i.e. the qualification (high school diploma) which formally entitles the student to be enrolled at Sapienza (as Bachelor student). Finally, for students who obtained their prior education in Italy, the type of highschool diploma and high-school final grade are also available.

As there are relatively few Italian students who obtained their higher education abroad (63 students, $0.4 \%$ ), they have not been included in the analysis. Hence, the final student population analysed consists of 15,203 individuals: 14,380 Italian students, 454 SGs, and 369 ISs. Table 2 shows the distribution of the students according to their profiles, their socio-demographic characteristics and their academic performances.

\footnotetext{
${ }^{1}$ Note that in the Italian tertiary system, some study programmes, called "single cycle programmes" (Corsi a ciclo unico), last 5 or 6 years. Students enrolled in these programmes were not included in the analysis.
} 
Table 2 Student demographic and academic characteristics by profile and gender (\% by column)

\begin{tabular}{|c|c|c|c|c|c|c|c|c|}
\hline \multirow[t]{2}{*}{ Variables } & \multicolumn{2}{|c|}{ Italians } & \multicolumn{2}{|l|}{ SGs } & \multicolumn{2}{|l|}{ ISs } & \multicolumn{2}{|l|}{ Total } \\
\hline & $M$ & $\mathrm{~F}$ & $M$ & $\mathrm{~F}$ & M & $\mathbf{F}$ & $M$ & $\mathbf{F}$ \\
\hline \multicolumn{9}{|l|}{ Geographical area of citizenship } \\
\hline Italy & 100.0 & 100.0 & 0.0 & 0.0 & 0.0 & 0.0 & 95.8 & 93.6 \\
\hline Romania & $-^{\mathrm{a}}$ & - & 30.8 & 34.7 & 4.1 & 16.6 & 0.8 & 1.7 \\
\hline Eastern Europe & - & - & 32.0 & 34.4 & 8.2 & 30.3 & 1.0 & 2.1 \\
\hline Africa & - & - & 8.9 & 6.7 & 31.2 & 5.7 & 0.8 & 0.4 \\
\hline Asia & - & - & 8.9 & 10.2 & 48.4 & 28.3 & 1.1 & 1.2 \\
\hline Latin America & - & - & 16.0 & 10.5 & 4.9 & 10.1 & 0.5 & 0.7 \\
\hline Western countries & - & - & 3.6 & 3.5 & 3.3 & 8.9 & 0.2 & 0.4 \\
\hline \multicolumn{9}{|l|}{ Place of domicile at enrolment } \\
\hline Rome & 43.3 & 40.6 & 50.9 & 48.1 & 51.6 & 55.1 & 43.7 & 41.3 \\
\hline out Rome & 56.7 & 59.4 & 49.1 & 51.9 & 48.4 & 44.9 & 56.3 & 58.7 \\
\hline \multicolumn{9}{|l|}{ Type of high-school diploma ${ }^{b}$} \\
\hline Classical and Scientific Lyceum & 64.3 & 61.6 & 27.2 & 38.9 & - & - & 62.2 & 59.9 \\
\hline Other Lyceum & 4.47 & 19.2 & 6.5 & 18.6 & - & - & 4.4 & 18.6 \\
\hline Technical or vocational high school & 31.2 & 18.2 & 66.3 & 42.5 & - & - & 31.5 & 18.5 \\
\hline Foreign high school & - & - & - & - & 100.0 & 100.0 & 1.8 & 3.0 \\
\hline \multicolumn{9}{|l|}{ Disciplinary area ${ }^{c}$} \\
\hline Architecture & 2.5 & 2.1 & 3.0 & 1.4 & 6.6 & 2.0 & 2.6 & 2.1 \\
\hline Economics & 10.5 & 6.6 & 15.4 & 15.8 & 16.4 & 7.3 & 10.7 & 6.9 \\
\hline Humanities & 15.4 & 27.6 & 13.6 & 31.9 & 18.0 & 37.7 & 15.4 & 28.1 \\
\hline Social sciences & 11.5 & 13.4 & 13.6 & 17.5 & 18.0 & 23.5 & 11.6 & 13.9 \\
\hline Engineering, informatics and statistics & 26.4 & 7.3 & 34.3 & 6.0 & 27.1 & 6.1 & 26.6 & 7.3 \\
\hline Healthcare professions and psychology & 21.8 & 31.5 & 14.8 & 19.7 & 8.2 & 18.2 & 21.4 & 30.7 \\
\hline Scientific disciplines & 12.0 & 11.5 & 5.3 & 7.7 & 5.7 & 5.3 & 11.7 & 11.2 \\
\hline \multicolumn{9}{|l|}{ Scholarship } \\
\hline Scholarship holder & 6.3 & 7.9 & 18.3 & 14.7 & 57.4 & 32.8 & 7.5 & 8.9 \\
\hline \multicolumn{9}{|l|}{ Student status } \\
\hline Still enrolled & 31.0 & 25.0 & 50.9 & 43.2 & 54.9 & 54.3 & 31.9 & 26.4 \\
\hline BAs & 43.2 & 52.3 & 25.4 & 38.6 & 23.0 & 29.6 & 42.4 & 51.1 \\
\hline of which time-to-degree $<=41$ months $^{\text {d }}$ & 41.8 & 45.2 & 34.9 & 36.4 & 28.6 & 21.9 & 41.6 & 44.6 \\
\hline Drop-out & 22.7 & 20.2 & 22.5 & 17.5 & 18.0 & 12.6 & 22.6 & 19.9 \\
\hline Transfer & 3.2 & 2.6 & 1.2 & 0.7 & 4.1 & 3.6 & 3.1 & 2.5 \\
\hline Mean high-school diploma grade ${ }^{b}(/ 100)$ & 75.4 & 78.5 & 72.4 & $75.9 \%$ & - & - & 75.4 & 78.4 \\
\hline Classical and Scientific Lyceum & 76.0 & 79.1 & 71.6 & 76.9 & & & 75.9 & 79.1 \\
\hline Other Lyceum & 74.1 & 77.5 & 75.5 & 74.3 & - & - & 74.2 & 77.4 \\
\hline Technical or vocational high school & 74.5 & 77.5 & 72.4 & 75.8 & - & - & 74.4 & 77.4 \\
\hline Mean age at enrolment & 20.5 & 20.1 & 21.2 & 20.9 & 24.6 & 25.3 & 20.6 & 20.3 \\
\hline Time-to-degree $<=41$ months ${ }^{\mathrm{d}}$ & 20.2 & 19.6 & 20.4 & 20.7 & 23.8 & 25.8 & 20.2 & 19.7 \\
\hline Time-to-degree $>41$ months ${ }^{d}$ & 19.9 & 19.7 & 20.2 & 20.6 & 24.9 & 25.2 & 19.9 & 19.9 \\
\hline Mean of the final grade (total) ${ }^{d}$ & 99.7 & 102.2 & 94.9 & 99.2 & 92.5 & 96.1 & 99.6 & 102.0 \\
\hline Time-to-degree $<=41$ months & 104.1 & 105.4 & 99.8 & 103.4 & 94.4 & 101.3 & 103.9 & 105.4 \\
\hline Time-to-degree $>41$ months & 96.6 & 99.6 & 92.3 & 96.7 & 91.2 & 94.6 & 96.5 & 99.4 \\
\hline Mean follow-up time total (in months) & 48.4 & 46.5 & 54.8 & 54.8 & 57.5 & 59.5 & 48.7 & 47.1 \\
\hline Time-to-degree $<=75$ months & 45.7 & 44.5 & 47.9 & 46.7 & 48.6 & 50.1 & 45.8 & 44.7 \\
\hline drop-out $<=75$ months & 20.7 & 19.7 & 19.2 & 24.3 & 23.8 & 23.1 & 20.7 & 19.9 \\
\hline transfer $<=75$ months & 22.1 & 19.1 & 12.1 & 13.8 & 21.9 & 30.3 & 22.0 & 19.6 \\
\hline Enrolled students ( $N$ ) & 6557 & 7823 & 169 & 285 & 122 & 247 & 6848 & 8355 \\
\hline
\end{tabular}

Source Authors' elaboration on administrative data of Sapienza University of Rome SGs second-generation students; ISs international students 
Table 2 (continued)

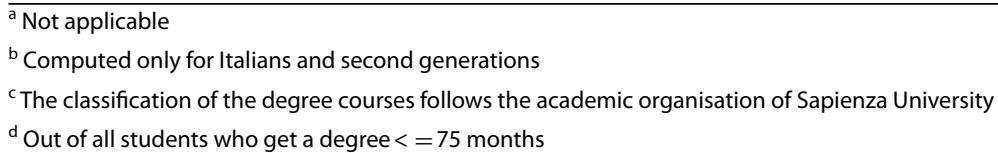

Academic performance has been captured both in terms of ability to complete the degree programme within 6 academic years and the quality of academic performance. The former has been measured by the variable "student status", based on the administrative student situation, which takes four categories: the student can get the BA degree (as of the 3rd year); drop-out; transfer to another university; or can still be enrolled at the end of the observation. In particular, the formal drop-out consists of an official withdrawal from the studies that is submitted by the student and entails the cancellation of the student's whole academic career. After withdrawing from their studies, students may enrol again in the same or another degree programme.

The quality of academic performance has been measured by both the final grade and the time-to-degree. The final grade, which incorporates scores both on course exams and for the final thesis, is expressed on a 110-point scale, with 66 being the minimum for a degree to be awarded. Time-to-degree is the number of months from the student's first enrolment to the month he/she obtains the BA degree.

Foreign students (both SGs and ISs) represent 5.4\% of the total student population. It should be noted that $54 \%$ of Italian students, $63 \%$ of ISs and $67 \%$ of SGs are women. Italian students are, on average, younger than the other two profiles, and SGs are, on average, younger than ISs. The first two groups access tertiary education at around the canonical age of 20-21 years, with a small gap in favour of Italian students. ISs are, instead, the oldest group at enrolment (24.9 years, on average), with minor gender differences. As regards the citizenship of foreign students, among SGs, more than half come from Eastern Europe (mainly Romania), followed by students from non-Western countries (from Asia, Latin America and Africa) and a small percentage from Western countries. Conversely, international students are almost equally distributed among nonWestern and Eastern European countries, with 28\% coming from Asia.

The intersection of profile, geographical area of citizenship and gender reveals that among ISs, almost half of men come from Asian and one third from African countries. Women, on the other hand, come mainly from Eastern European countries. With SGs there are no gender differences in terms of origin countries.

Most Italian students live outside Rome, the city in which Sapienza is located, whereas foreign students are more likely to live in the city, there being no differences between men and women in this respect.

As far as the type of high school, among men, second-generation students come mainly from Technical or Vocational schools, while women are more likely to come out of the Lyceum system. Overall, women attend more than men Lyceums other than Classical and Scientific. Among second-generation women, the great majority (around 80\%) is equally distributed between Technical or Vocational High-School and Classical and Scientific Lyceum.

There are also gender differences in the enrolment according to the disciplinary area and the profile. Among second-generation students, the gender gap, in favour of males in 
Engineering, Informatics and Statistics, and in favour of females in Humanities, is larger than that registered within Italians and IS. In contrast, the gap is smaller in Healthcare professions and Psychology and Economics among SG than Italians.

Almost half of students get the BA degree within 75 months. Among them, most are Italians, followed by SG and IS. The latter show a higher percentage of students who do not get the degree with respect to the other two groups. In all three profiles analysed, women achieve higher completion rates (especially among Italians, 52.3\%) and lower drop-out rates than men. As regards the transferring to another university, percentages are smaller than the other outcomes. The highest percentage is registered among IS (4.1\% among men; $3.6 \%$ among women). The proportion drops to $0.7 \%$ among female SGs.

Women have on average higher final grades than men, but the gender gap is greater among SGs. Moreover, the distance between SG and Italian students is less than the distance between Italians and ISs, especially among students who get the degree within 41 months. ${ }^{2}$ Finally, both SGs and ISs have longer time-to-degree scores than Italians, with similar gender gaps.

For this study, we applied two separate analyses. This allows us to explore student careers from a quantitative and qualitative perspective. The first perspective looks at the probability to get the BA degree or not, considering the competing risks of dropping-out or transferring to another university. The second perspective looks at successful students (those who get the BA degree) with the aim of analysing the main predictors of their final grade and time-to-degree.

In the first stage, we estimated survival probabilities for men and for women starting from the enrolment (1st October 2012), with monthly details, to explore differences in getting the BA degree drop-outs or transfers to other universities between Italian and foreign students. Individuals who did not get the degree, drop-out or transfer to another university during the 75 months of follow-up were censored. We applied a discrete-time competing risk hazard model in a multinomial logistic regression structure for evaluating the competing nature of getting the BA degree, drop-out, transfer versus being still enrolled (Agodini \& Deke, 2004; Allison, 2010).

Following Allison (1982), discrete-time competing risk hazard models allow us to take into account $n$ possible ways of exiting the base state. In our case, there are three possibilities for exiting the university enrolment state (BA degree, drop-out, or transfer).

Including the base state, there are $n+1$ alternative states and they are indexed by $k=0$, $\ldots, n$. We can define $K$ as a random variable indicating the particular state at time $T$. The discrete-time hazard rate for exiting the base state by means $k$ at time $t$ can be defined as $P=(T=t, K=k \mid T>t-1), k>0$. This equation states that the hazard of exiting via means $K$ at time $T$ is the probability of doing so given survival up to at least time $T$. The model is specified as follows:

$$
P(T=t, K=k \mid T>t-1)=\frac{\exp \left[\alpha_{k t}+\beta_{k}^{\prime} x\right]}{\left(1+\sum_{k=1}^{n} \exp \left[\alpha_{k t}+\beta_{k}^{\prime} x\right]\right)} \quad \forall k \in \text { setofexit states, }
$$

\footnotetext{
${ }^{2}$ Which means 3 years +5 months to take into account the additional time elapsing from the end of the academic year to the BA degree exam, for BAs who completed their studies on time.
} 


$$
P(T>t \mid T>t-1)=\frac{1}{\left(1+\sum_{k=1}^{n} \exp \left[\alpha_{k t}+\beta_{k}^{\prime} x\right]\right)} \quad k=\text { continue. }
$$

We considered how this hazard rate is a function of time $\left(\alpha_{k t}\right)$ and a vector of timeinvariant explanatory variables ( $x$ with its coefficient vector $\beta_{k}$ ). More specifically, the model was used to determine how a set of explanatory variables (associated with student profile, student demographic characteristics, and student academic ability ${ }^{3}$ ) affected BA graduation (where dropping-out and transferring are treated as competing risks), dropout (where BA graduation and transferring are treated as competing risks), and transfer (where BA graduation and dropping-out are treated as competing risks), versus the still enrolment state.

Individual observations were reshaped into a person-month format. Subsequently, for the sake of the analysis, months were grouped in periods. The first period corresponds to the course's legal duration ( 3 years); the subsequent periods correspond to the following six semesters. This time-frame is appropriate to mark time in an educational setting.

The dependent variable is the student status with four modalities: students who are still enrolled after $t$ months, with $t$ varying from 1 to exit time or 75 months, are considered the reference group (0). Then, the model estimates the probability to experience one of the events during the follow-up period: BAs (1); drop-out (2); and transfer to another university (3). The main explanatory variable is the student profile: SGs vs. Italians; and ISs vs. Italians. Models estimate the association between explanatory variables and the likelihood of getting the BA degree, drop-out, transfer, versus being still enrolled (the reference category). First, we estimated a model for the total cohort of students to explore differences between Italians, SGs, and ISs (Table 3). Second, models were estimated separately for men and women to explore whether differences between the three profiles also persisted within the male and the female populations (Table 4); finally, models were estimated by student profiles to explore the role of the geographical area of citizenship on student status (Table 5).

In the second stage of the analysis, the Classification and Regression Tree (CART, Breiman et al., 1984), which is a non-parametric tree-structured recursive partitioning method, is applied to a total of $7173 \mathrm{BAs}$, with the aim of predicting both the final grade and time-to-degree on the basis of the predictors observed in a training sample of the data. The main idea behind a Regression Tree is to recursively split data into groups on the basis of one predictor at a time, so that, step by step, smaller and smaller strata are obtained with an increasingly low degree of impurity. The optimal split is found over all predictors at all possible split points.

After growing the tree, when no more splits are possible, a pruning phase for the algorithm is performed to select the best subtree with a reduced number of terminal nodes (leaf nodes) which prevents overfitting. The tree is grown using the Residual Sum of Squares (RSS) criterion, and cost-complexity pruning with a tenfold cross validation is performed.

\footnotetext{
${ }^{3}$ Note that the categories "Classical and Scientific Lyceum" and "Other Lyceum" have been merged here into "Lyceum" due to the small sample size of "Other Lyceum".
} 
Table 3 Relative risk ratios from discrete-time multinomial logistic regression of student status for Sapienza students enrolled in the a.y. 2012/2013

\begin{tabular}{|c|c|c|c|}
\hline & $\begin{array}{l}\text { BA degree vs. still- } \\
\text { enrolled }\end{array}$ & $\begin{array}{l}\text { Drop-out vs. still- } \\
\text { enrolled }\end{array}$ & $\begin{array}{l}\text { Transfer } \\
\text { vs. still- } \\
\text { enrolled }\end{array}$ \\
\hline & RRR & RRR & RRR \\
\hline \multicolumn{4}{|l|}{ Profile } \\
\hline Italians & Ref. & Ref. & Ref. \\
\hline ISs & $0.51^{* * *}$ & $0.58^{* * *}$ & 1.58 \\
\hline SGs & $0.59^{* * *}$ & $0.81^{*}$ & $0.29 * *$ \\
\hline \multicolumn{4}{|l|}{ Gender } \\
\hline M & Ref. & Ref. & Ref. \\
\hline W & $1.25^{* * *}$ & 0.98 & 0.92 \\
\hline Age & $0.92^{* * *}$ & 1.00 & $0.93^{* * *}$ \\
\hline \multicolumn{4}{|l|}{ Place of domicile at enrolment } \\
\hline Out of Rome & Ref. & Ref. & Ref. \\
\hline In Rome & 0.99 & 0.96 & 0.94 \\
\hline \multicolumn{4}{|l|}{ Disciplinary area } \\
\hline Architecture & $1.27^{* *}$ & $0.51^{* * *}$ & $0.45^{* *}$ \\
\hline Economics & Ref. & Ref. & Ref. \\
\hline Humanities & 0.96 & $0.83^{* *}$ & $0.39^{* * *}$ \\
\hline Social sciences & $0.83^{* * *}$ & 1.03 & $0.52^{* * *}$ \\
\hline Engineering, informatics and statistics & 1.02 & 1.02 & $0.65^{* *}$ \\
\hline Healthcare professions and psychology & $1.78^{* * *}$ & $0.47^{* * *}$ & $0.39^{* * *}$ \\
\hline Scientific disciplines & $0.90^{*}$ & $1.68^{* * *}$ & $0.58^{* *}$ \\
\hline \multicolumn{4}{|l|}{ Scholarship } \\
\hline No & Ref. & Ref. & Ref. \\
\hline Yes & $1.36^{* * *}$ & 0.99 & 0.95 \\
\hline \multicolumn{4}{|l|}{ Time in months } \\
\hline $1-33$ & $0.02^{* * *}$ & $2.35^{* * *}$ & 1.25 \\
\hline 34-39 & Ref. & Ref. & Ref. \\
\hline $40-45$ & $0.82^{* * *}$ & $0.53^{* * *}$ & $0.03^{* * *}$ \\
\hline $46-51$ & $0.65^{* * *}$ & 1.14 & $0.59^{*}$ \\
\hline $52-57$ & $0.42^{* * *}$ & $0.43^{* * *}$ & 0.01 \\
\hline $58-63$ & $0.33^{* * *}$ & 1.17 & 0.62 \\
\hline $64-72$ & $0.19^{* * *}$ & $0.76^{* *}$ & $0.20^{* * *}$ \\
\hline
\end{tabular}

Source Authors' elaboration on administrative data of Sapienza University of Rome

${ }^{*} p<0.1 ;{ }^{* *} p<0.05 ;{ }^{* * *} p<0.001$

$S G$ second-generation students; ISs international students

${ }^{\text {a }}$ The classification of the degree courses follows the academic organisation of Sapienza University

The use of trees offers several advantages: more efficiency in dealing with high dimension data than parametric regression; no assumptions about the data; handling predictors of mixed types (categorical and continuous); ease of interpretation with the aid of graphical representation.

The regression trees in Figs. 1 and 2 are built by using the demographic and academic characteristics of the BAs as predictors, namely: gender; age; domicile at enrolment; scholarship; area of citizenship; and country of prior education. This allows for the identification of the main variables and their possible interactions which are relevant as determinants of, respectively, the final grade and the time-to-degree. 
Table 4 Relative risk ratios from discrete-time multinomial logistic regression of student status for men and women

\begin{tabular}{|c|c|c|c|c|c|c|}
\hline & \multicolumn{3}{|l|}{ Men } & \multicolumn{3}{|l|}{ Women } \\
\hline & $\begin{array}{l}\text { BA degree vs. } \\
\text { still-enrolled }\end{array}$ & $\begin{array}{l}\text { Drop-out vs. } \\
\text { still-enrolled }\end{array}$ & $\begin{array}{l}\text { Transfer vs. } \\
\text { still-enrolled }\end{array}$ & $\begin{array}{l}\text { BA degree vs. } \\
\text { still-enrolled }\end{array}$ & $\begin{array}{l}\text { Drop-out vs. } \\
\text { still-enrolled }\end{array}$ & $\begin{array}{l}\text { Transfer } \\
\text { vs. still- } \\
\text { enrolled }\end{array}$ \\
\hline & RRR & RRR & RRR & RRR & RRR & RRR \\
\hline \multicolumn{7}{|l|}{ Profile } \\
\hline Italians & Ref. & Ref. & Ref. & Ref. & Ref. & Ref. \\
\hline ISs & $0.49^{* *}$ & $0.67^{*}$ & 1.60 & $0.52^{* * *}$ & $0.54^{* * *}$ & 1.53 \\
\hline SGs & $0.50^{* * *}$ & 0.91 & 0.36 & $0.64^{* * *}$ & $0.76^{*}$ & $0.24^{* *}$ \\
\hline Age & $0.92^{* * *}$ & 1.01 & $0.89^{* * *}$ & $0.92^{* * *}$ & 0.99 & $0.96^{*}$ \\
\hline \multicolumn{7}{|c|}{ Time in month } \\
\hline $1-33$ & $0.01^{* * *}$ & $2.09^{* * *}$ & 0.90 & $0.02^{* * *}$ & $2.65^{* * *}$ & $1.98^{* *}$ \\
\hline $34-39$ & Ref. & Ref. & Ref. & Ref. & Ref. & Ref. \\
\hline $40-45$ & $0.74^{* * *}$ & $0.41^{* * *}$ & 0.01 & $0.88^{* *}$ & $0.69^{*}$ & $0.10^{* *}$ \\
\hline $46-51$ & $0.66^{* * *}$ & 0.98 & $0.44^{*}$ & $0.63^{* * *}$ & $1.35^{*}$ & 0.90 \\
\hline $52-57$ & $0.40^{* * *}$ & $0.42^{* * *}$ & 0.01 & $0.44^{* * *}$ & $0.44^{* *}$ & 0.01 \\
\hline $58-63$ & $0.38^{* * *}$ & 0.89 & $0.49^{*}$ & $0.29^{* * *}$ & $1.51^{* *}$ & 0.85 \\
\hline $64-72$ & $0.19^{* * *}$ & $0.55^{* * *}$ & $0.12^{* * *}$ & $0.19^{* * *}$ & 1.04 & $0.39^{*}$ \\
\hline
\end{tabular}

The model controls for place of domicile at enrolment, disciplinary area and scholarship

Source Authors' elaboration on administrative data of Sapienza University of Rome

SGs second-generation students; ISs international students

${ }^{*} p<0.1 ;{ }^{* *} p<0.05 ;{ }^{* *} p<0.001$

In order to adjust for potential bias due to existing structural differences among study programmes, differences which could mask the differential behaviours between Italian and foreign BAs, we normalised final grades and the time-to-degree. Specifically, final grades are defined as the ratio between the final grade and its median value within each faculty; similarly, time-to-degree is defined as the ratio between the time-to-degree and its median value within each faculty. The use of the median rather than the mean has been preferred to avoid the strong influence of the outliers. These could skew the central measure as a reference of the distribution of both time-to-degree and final grade.

\section{Results}

\section{Discrete-time survival analysis}

Table 3 shows relative risk ratios (RRR) from the multinomial logistic regressions for the total cohort of students predicting the likelihood of either a BA degree, a drop-out or a transfer to another university with respect to being still enrolled during the follow-up. These three outcomes are treated as competing risks.

As expected, net of demographic and academic variables, student profiles were associated with the three types of student status: both ISs and SGs are less likely to get the BA degree $(R R R=0.51$ and 0.59 , respectively) and drop-out $(R R R=0.58$ and 0.81$)$ than being still enrolled, relative to Italian students. SGs also have very low risks of transferring relative to Italians $(R R R=0.29)$. When the model is performed for the two genders separately (Table 4), a similar pattern is confirmed for women. In contrast, among men, results show that ISs and SGs are linked to a lower risk of getting the BA degree, and 
Table 5 Relative risk ratios from discrete-time multinomial logistic regression of student status by profile

\begin{tabular}{|c|c|c|c|c|c|}
\hline BA degree vs. still enrolled & Italians & SGs (1) & SGs (2) & ISs (1) & $\begin{array}{l}\text { ISs (2) } \\
\text { RRR }\end{array}$ \\
\hline \multicolumn{6}{|l|}{ Gender } \\
\hline M & Ref. & Ref. & Ref. & Ref & Ref. \\
\hline W & $1.06^{* *}$ & $1.29^{*}$ & 1.26 & 1.41 & 1.22 \\
\hline Age & $0.94^{* * *}$ & $0.94^{*}$ & 0.95 & 1.00 & 1.00 \\
\hline \multicolumn{6}{|l|}{ High-school diploma ${ }^{\mathrm{a}, \mathrm{b}}$} \\
\hline Other Italian high schools & Ref. & Ref. & Ref. & & \\
\hline Lyceum & $1.53^{* * *}$ & $1.57^{* *}$ & $1.64^{* *}$ & & \\
\hline \multicolumn{6}{|l|}{ Geographical area of citizenship } \\
\hline Romania & & & Ref. & & Ref. \\
\hline Eastern Europe & & & 1.02 & & 0.82 \\
\hline non-Western countries & & & $0.72^{*}$ & & $0.54^{*}$ \\
\hline Western countries & & & n.r. & & n.r. \\
\hline \multicolumn{6}{|l|}{ Time in months } \\
\hline $1-33$ & $0.02^{* * *}$ & $0.01^{* * *}$ & $0.01^{* * *}$ & $0.03^{* * *}$ & $0.03^{* * *}$ \\
\hline $34-39$ & Ref. & Ref. & Ref. & Ref. & Ref. \\
\hline $40-45$ & $0.86^{* * *}$ & 0.86 & 0.88 & 0.94 & 0.94 \\
\hline $46-51$ & $0.67^{* * *}$ & 0.94 & 0.96 & $1.81^{* *}$ & $1.82^{* *}$ \\
\hline $52-57$ & $0.45^{* * *}$ & $0.44^{* *}$ & $0.45^{* *}$ & 0.78 & 0.79 \\
\hline $58-63$ & $0.35^{* * *}$ & $0.44^{* *}$ & $0.45^{* *}$ & 0.59 & 0.61 \\
\hline $64-72$ & $0.20^{* * *}$ & $0.31^{* * *}$ & $0.32^{* * *}$ & $0.48^{* *}$ & $0.48^{* *}$ \\
\hline \multicolumn{6}{|l|}{ Drop-out vs. still enrolled } \\
\hline \multicolumn{6}{|l|}{ Gender } \\
\hline M & Ref. & Ref. & Ref. & Ref. & Ref. \\
\hline W & $1.09^{* *}$ & 0.91 & 0.89 & 0.78 & 0.86 \\
\hline Age & $0.99^{* *}$ & 0.97 & 0.97 & 1.02 & 1.03 \\
\hline \multicolumn{6}{|l|}{ High-school diploma $a^{\mathrm{a}, \mathrm{b}}$} \\
\hline Other Italian high schools & Ref. & Ref. & Ref. & & \\
\hline Lyceum & $0.81^{* * *}$ & $0.69^{*}$ & $0.69^{*}$ & & \\
\hline \multicolumn{6}{|l|}{ Geographical area of citizenship } \\
\hline Romania & & & Ref. & & Ref. \\
\hline Eastern Europe & & & n.r. & & 2.42 \\
\hline non-Western countries & & & 0.70 & & $2.89^{*}$ \\
\hline Western countries & & & n.r. & & n.r. \\
\hline \multicolumn{6}{|l|}{ Time in months } \\
\hline $1-33$ & $2.38^{* * *}$ & 1.78 & 1.77 & $3.28^{*}$ & $3.27^{*}$ \\
\hline $34-39$ & Ref. & Ref. & Ref. & Ref. & Ref. \\
\hline $40-45$ & $0.52^{* * *}$ & 0.37 & 0.37 & 1.07 & 1.06 \\
\hline $46-51$ & 1.11 & 0.39 & 0.40 & 2.35 & 2.34 \\
\hline $52-57$ & $0.43^{* * *}$ & 0.21 & 0.21 & 0.01 & 0.01 \\
\hline $58-63$ & 1.09 & 1.11 & 1.11 & 1.99 & 1.98 \\
\hline $64-72$ & $0.76^{* *}$ & 0.35 & 0.35 & 0.35 & 0.34 \\
\hline \multicolumn{6}{|l|}{ Transfer vs. still enrolled } \\
\hline \multicolumn{6}{|l|}{ Gender } \\
\hline M & Ref. & Ref. & Ref. & Ref. & Ref. \\
\hline W & 0.86 & 2.42 & 1.23 & 1.17 & 1.85 \\
\hline Age & $0.92^{* * *}$ & 1.02 & 1.17 & 1.01 & 0.99 \\
\hline
\end{tabular}


Table 5 (continued)

\begin{tabular}{|c|c|c|c|c|c|}
\hline \multirow[t]{2}{*}{ BA degree vs. still enrolled } & Italians & SGs (1) & SGs (2) & ISs (1) & ISs (2) \\
\hline & RRR & RRR & RRR & RRR & RRR \\
\hline \multicolumn{6}{|l|}{ High-school diploma $a^{\mathrm{a}, \mathrm{b}}$} \\
\hline Other Italian high schools & Ref. & Ref. & Ref. & & \\
\hline Lyceum & $1.60^{* * *}$ & 0.02 & 0.03 & & \\
\hline \multicolumn{6}{|l|}{ Geographical area of citizenship } \\
\hline Romania & & & Ref. & & Ref. \\
\hline Eastern Europe & & & n.r. & & 0.11 \\
\hline non-Western countries & & & 0.06 & & 0.01 \\
\hline Western countries & & & n.r. & & n.r. \\
\hline \multicolumn{6}{|l|}{ Time in months } \\
\hline $1-33$ & 1.29 & 1.02 & 1.04 & 0.47 & 0.47 \\
\hline $34-39$ & Ref. & Ref. & Ref. & Ref. & Ref. \\
\hline $40-45$ & $0.04^{* * *}$ & 0.94 & 0.93 & 0.01 & 0.01 \\
\hline $46-51$ & $0.57^{*}$ & 0.95 & 1.06 & 0.82 & 0.78 \\
\hline $52-57$ & 0.01 & 0.89 & 1.08 & 0.02 & 0.02 \\
\hline $58-63$ & 0.70 & 0.86 & 1.24 & 0.01 & 0.01 \\
\hline $64-72$ & $0.23^{* * *}$ & 0.82 & 1.56 & 0.02 & 0.06 \\
\hline \multicolumn{6}{|c|}{$\begin{array}{l}\text { The model controls also for place of domicile at enrolment, disciplinary area, scholarship and diploma grade (only for } \\
\text { Italians and SGs) }\end{array}$} \\
\hline \multicolumn{6}{|c|}{ SGs/ISs (1): models do not control for origin area; SGs/ISs (2): models control for origin area } \\
\hline \multicolumn{6}{|c|}{ Source Authors' elaboration on administrative data of Sapienza University of Rome } \\
\hline \multicolumn{6}{|c|}{$\begin{array}{l}\text { SGs second-generation students; ISs international students; } n . r \text {. coefficients are not reported because computed on less than } \\
10 \text { observations }\end{array}$} \\
\hline \multicolumn{6}{|c|}{${ }^{*} p<0.1 ;{ }^{* *} p<0.05 ;{ }^{* * *} p<0.001$} \\
\hline \multicolumn{6}{|c|}{ a Computed only for Italians and second generations } \\
\hline $\begin{array}{l}\text { b "Classical and Scientific Lyceum } \\
\text { "Other Lyceum" }\end{array}$ & her Lyceum & & & & \\
\hline
\end{tabular}

only ISs are linked to a marginally $(p<0.1)$ lower risk of dropping-out, compared with being still enrolled, relative to Italians. One must bear in mind that caution is needed in interpreting results on migrant-native differentials, because they might be due to the different sample sizes. As regards the likelihood of transferring to another university, no gender differences were detected among the three profiles. Moreover, as expected, results suggest that women get the BA degree faster than men (Table 4).

The estimation by student profile is presented in Table 5 . Here the information on high school is included only for SG and Italian students because this kind of information is not available for students who got their diploma abroad. Moreover, for non-Italian students, the area of origin is taken into account. In this regard, two models are presented: model 1 (SG (1) and IS (1)) includes only demographic and academic characteristics. In model 2 (SG (2) and IS (2)) the origin area is added.

Like Italian students, for SGs the high school track is associated with BA graduation. Indeed, those who have a Lyceum diploma have a higher risk of getting the BA degree, compared to those with a Technical or Vocational diploma (Italians: RRR=1.53; SGs (1): $R R R=1.57$; $S G s(2): R R R=1.64)$. Conversely, the age at enrolment is negatively associated with obtaining the BA degree (only among Italian and SG (1) students), dropout and transfer to another university (for Italians). Moreover, Model SG (1) suggests that SG women have a marginally $(p<0.1)$ higher risk of getting the BA degree than SG men, following the same pattern as Italian students. Nonetheless, when citizenship is 


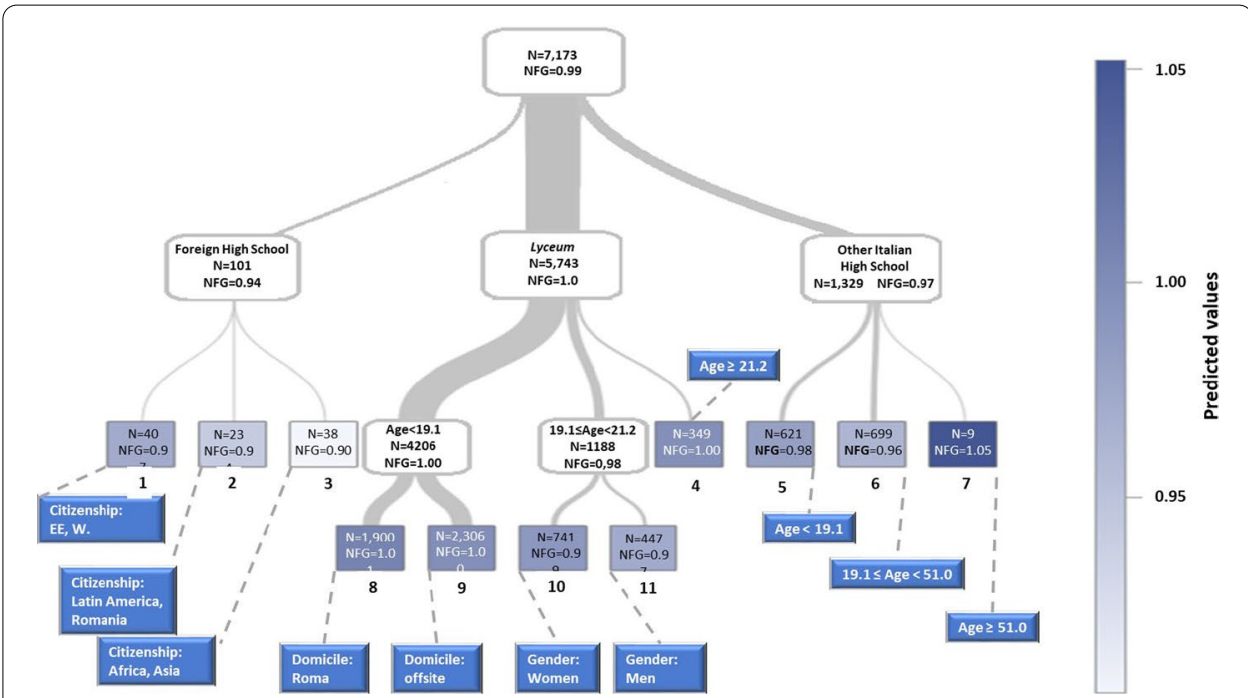

Fig. 1 Tree plot for the normalised final grade - total population. N absolute number of BAs; NFG average normalised final grade; EE Eastern Europe; WWestern countries

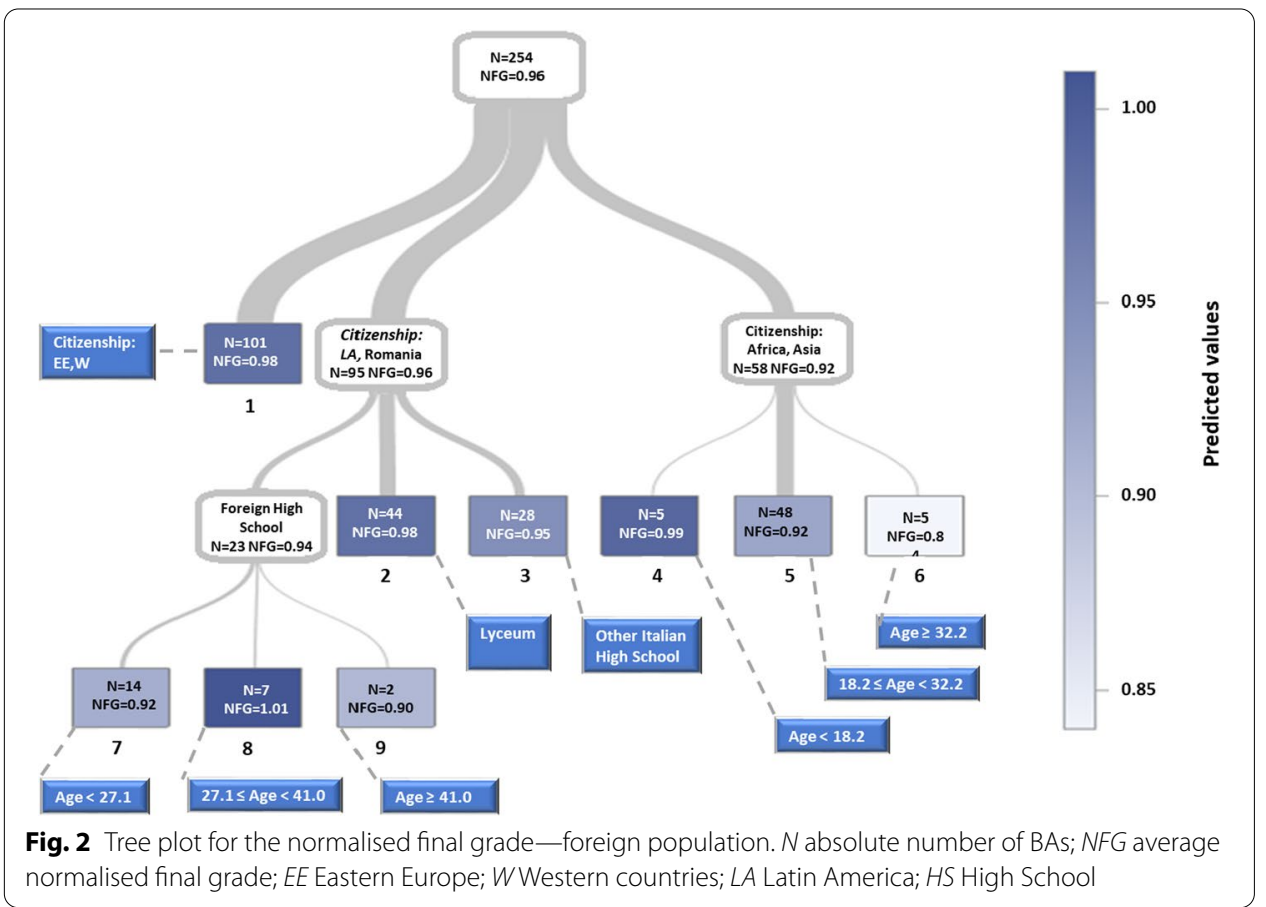

introduced into the analysis, (Model SG (2)), this result turns out to be not significant and a higher risk of getting the BA degree is associated with the Romanian students as opposed to Asians, Africans, Latin Americans and students from Western countries.

Concerning the time-to-degree, the analysis suggests that Italian students are more likely to get the BA degree in a shorter time than their foreign counterparts. 
Table 6 Importance of independent variables for regression trees for final grade

\begin{tabular}{|c|c|c|c|c|c|}
\hline \multicolumn{6}{|l|}{ Final grade } \\
\hline \multicolumn{3}{|l|}{ Total population } & \multicolumn{3}{|l|}{ Foreign population } \\
\hline Independent variable & Importance & $\begin{array}{l}\text { Relative } \\
\text { importance } \\
(\%)\end{array}$ & Independent variable & Importance & $\begin{array}{l}\text { Relative } \\
\text { importance } \\
(\%)\end{array}$ \\
\hline $\begin{array}{l}\text { Type of high-school } \\
\text { diploma }\end{array}$ & 1.0245 & 100.00 & $\begin{array}{l}\text { Geographical area of } \\
\text { citizenship }\end{array}$ & 0.3645 & 100.00 \\
\hline Age & 0.7389 & 72.12 & Age & 0.3208 & 88.00 \\
\hline Domicile & 0.3300 & 32.20 & $\begin{array}{l}\text { Type of high-school } \\
\text { diploma }\end{array}$ & 0.1730 & 47.44 \\
\hline $\begin{array}{l}\text { Geographical area of } \\
\text { citizenship }\end{array}$ & 0.3027 & 29.54 & & & \\
\hline Gender & 0.2980 & 29.09 & & & \\
\hline
\end{tabular}

The analysis also suggests that the high school type has also a statistically significant effect on formal drop-out. Italian and SG students coming from Lyceum show a lower probability of dropping-out than those coming from Technical or Vocational schools. Unsurprisingly, and in line with the literature, the likelihood of dropping-out is greater in the first time-period. Results display that Italians are 2.4 times more likely to drop-out by the 33rd month. In the same time-period, ISs are 3.3 times more likely to experience such an event; SGs also show a higher risk even if the result is not significant. The analysis of the timing of transfer to another university does not detect any differences, except for Italians.

\section{Regression trees}

High-school diploma type is the most important predicting variable for the final grade for the total population of BAs, followed by, in decreasing order of importance: age at enrolment; place of domicile at enrolment; area of citizenship; and gender (Table 6). When the analysis is applied only to foreign students, the area of citizenship (Romania, other Eastern European Countries, Africa, Asia, Latin American, Western Countries) is the most important predicting variable. This is followed by age and Type of High-School Diploma (foreign diploma, Italian Lyceum, other Italian diplomas).

Figures 1 and 2 report the regression trees for, respectively, final grade for the total population and for foreign students: the predicted response value reported in each node is the average observed final grade normalised with respect to the median outcome within the student's faculty.

Looking at the total population (Fig. 1), the terminal nodes (leaves) have identified eleven groups of BAs and following the splitting path the best split is whether the student obtained the High-School diploma abroad or in Italy, distinguishing between Lyceum and other Italian diplomas. If abroad, the BA graduate is in the left node (101 individuals), whereas for Lyceum and for other Italian diplomas, he/she is in, respectively, the central and right node with 5743 and 1329 individuals.

Among the international BAs who earned a foreign high-school diploma, the best split is determined by the area of citizenship. Specifically, node 1 (40 individuals) is characterised by Eastern European and Western citizens with the highest predicted response value among ISs (0.97, corresponding to 98.23/110), together with node 2 (which 
includes 23 individuals from Latin America and Romania with average normalised final grade of 0.94, corresponding to 97.70/110). The remaining 38 ISs from Africa and Asia in node 3 achieved, overall, the lowest average grade of all BAs (0.90, corresponding to 90.16/110).

Among the BAs who obtained the Lyceum diploma, the best split is for whether the student's age at enrolment was younger than 19.1 years, between 19.1 and 21.2 years or older. For the younger BAs (4206 individuals), the following best distinction is whether they are "offsite" or not: those who live in Rome (1900 individuals in node 4) are characterised by a slightly higher average final grade (1.01 corresponding to $101.83 / 110)$ than those who are "offsite" with an average grade perfectly in line with their faculty's median grade (1.00 corresponding to 101.58/110).

A gender gap emerges only for BAs with a prior Lyceum diploma who enrolled between 19.1 and 21.2 years. These have generally lower final grades than their younger peers, and a better performance for women (741 individuals with average final grade value equal to 0.99 ) compared to men (447 individuals with an average final grade value of 0.97).

Finally, the remaining 1329 individuals with a non-Lyceum Italian high-school diploma are split by their age at enrolment. Those who enrolled younger (621 individuals in node 9) achieved higher average final grades (0.98) than those who enrolled when they were older (699 individuals in node 10 with average final grade equal to 0.96 ). The exception was for nine individuals in node 11 who entered University late but who, overall, performed best.

By analysing only foreign BAs (Fig. 2), the regression tree allows us to highlight different performances in terms of average final grades by distinguishing by large citizenship groups: BAs from Africa and Asia exhibit the lowest average normalised final grade. Only for BAs with South American and Romanian citizenship, a distinction emerges between IS and SG students. ISs are characterised by greater heterogeneity, and their differences depend mainly on age. The performances of SGs are, instead, more homogeneous with generally higher final grades: differences are, for the most part, related to the type of Italian High-School diploma (Lyceum: 0.98, i.e. 99.36/110, vs other Italian diplomas: 0.95 , i.e. $94.61 / 110$ ).

For the sake of brevity, results from the regression tree of the time-to-degree for all BAs are not reported here (Fig. 1A in Additional file 1: Appendix). The results confirm the decisive importance of the student's age at enrolment and the type of HighSchool diploma. Those with an Italian educational background are characterised by a lower average time-to-degree (normalised values equal to 1.04 and 1.09 for, respectively, Lyceum and other Italian diplomas) compared to their international colleagues (1.12). The analysis also confirms the role of gender, with women having lower time-to-degrees than men.

\section{Discussion and conclusions}

Following a cohort of 1st-year Bachelor students enrolled at Sapienza University, the present study investigated the academic performance of foreign students with an Italian educational background as compared to foreign students with a foreign educational background and Italian students. Specifically, the analysis focuses on the degree 
completion, the final grade and the time-to-degree, by applying discrete-time competing risk hazard models and regression trees.

We defined foreign students with a foreign educational background as international students (ISs), and foreign students with an Italian educational background as secondgeneration students (SGs).

The findings support our first hypothesis (H1) that students with foreign citizenship suffer from a relative disadvantage, and that SGs show an advantage with respect to ISs. Compared to Italian students, both SGs and ISs had significantly lower outcomes, for both genders. Nevertheless, results suggest that, in terms of educational performance, SGs are more similar to Italians than to ISs.

Looking at the geographical area of citizenship, students coming from non-Western countries show lower risk of getting the BA degree, for both SGs and Is. Following the notion of cultural distance (Furnham \& Alibhai, 1985), we can argue that students with a non-Western background experience higher psychological and socio-cultural stress, which might affect their academic performances.

It is worth noting that ISs are a highly heterogeneous group. They are composed of both students who come in the context of consolidated chain migration (Romanians, Latin Americans, Africans) and students who are mainly driven by internationalisation policies implemented by universities, having no specific connections to the country of destination. We might speculate that their academic success is associated with various aspects of their academic and social life, such as language barriers, socio-economic situation and psychological and socio-cultural adaptation (Baker \& Siryk, 1999; Rienties et al., 2012). These are, in turn, related to socio-demographic variables.

Conversely, SG students are a more homogenous group than ISs because of a common educational background and have overcome most difficulties in terms of educational integration. Nonetheless, our results show worse performances than Italians, in terms of the lower probability of getting the BA degree during the period analysed (Tables 2 and 3). We can interpret this result as a consequence of educational disadvantages that SGs have failed to shrug off. Unlike Italian students, the majority of SGs come from Technical or Vocational high schools. Moreover, one can observe that recently arrived students are often allocated to classes with younger peers, mainly to address their low language proficiency. This practice may have important implications for their degree, especially in terms of school delay, choices for shorter educational paths and early exits from school (Minello \& Dalla Zuanna, 2014). However, even after controlling for age at enrolment, a residual disadvantage persists and SGs still perform worse than Italian students. Further studies based on a qualitative approach are needed in order to deeply analyse the detected differences.

Both SGs and ISs have lower drop-out rates, even if this result is not significant among men. Nonetheless, since in our study information about the drop-out is retrieved from administrative data, and thus it refers to the official withdrawal from the studies, results must be interpreted with caution.

It is not surprising that the lowest drop-out rate is observed among international students. Indeed, for non-EU citizens holding a residence permit for study purposes, formal withdrawal entails the loss of such a permit. Therefore, it will prevent students from enrolling in other Italian universities in the same academic year. Moreover, to enrol in 
subsequent academic years, students must refer to the competent Italian Embassy or Consulate in their country of origin. A further reason for the observed figure concerns the fact that such a procedure is not required for students who decide to leave their courses and enrol at another university abroad: students who return to their countries of origin without getting the BA degree may continue to study without any formal application in Italy. Moreover, as international students face many challenges in attaining a university course abroad, they are generally highly motivated.

Concerning second-generation students, a lower willingness to formally drop out in respect to Italian students is also observed among SGs. This figure might be linked to the strong expectations of immigrant families versus the education career of their children, which might act as a deterrent from dropping out. This interpretation suggests the opportunity to further explore the reasons for formal and informal drop-out for secondgeneration students, using a qualitative approach.

Our second hypothesis (H2) about the existence of gender differences in academic performance within the foreign student population is confirmed. Overall, as expected, results show that women are more likely to get the BA degree (and less likely to drop-out or transfer) than men. In addition, the gender difference seems to be relevant among SGs. However, when we include the geographical area of citizenship in the model, the difference between the genders disappears. This might be related to the fact that controlling for the geographical area of citizenship implicitly accounts for gender differences in migrant subgroup composition.

Further research is needed in order to explain this pattern in the context analysed. We, though, can speculate that migration background enhances gender differences in education through a greater social control over daughters and that this pushes women more than men to succeed in school (Feliciano \& Rumbaut, 2005). Moreover, education may represent a special opportunity of self-fulfilment and empowerment for women (Lagomarsino \& Ravecca, 2014).

Finally, our results support the third hypothesis (H3) on the existence of differences linked to the geographical area of citizenship of the students and their families: both SGs and ISs belonging to communities that are better integrated in the Italian social and cultural context perform better. For instance, among SGs, Romanian students are more likely to get the BA degree than students belonging to families from non-Western countries.

The third hypothesis is partially confirmed by looking at ISs as well, with non-Western citizens showing the lowest risk of getting the BA degree and Western and Eastern European students showing the highest final grades. Indeed, as mentioned above, ISs include both selected students in terms of educational and socio-economic background, mainly from Western countries, and a highly heterogeneous group, from all-over the world, with very different backgrounds.

As far as BAs are concerned, results from regression trees about final grade and time-to-degree suggest that the disadvantage of SG disappears. This finding should be interpreted with caution and two considerations are needed here: first, BAs are a highly selected population. Indeed, the university experience perhaps helps selected students to overcome the obstacles found in the literature with reference to the educational paths of foreign nationals. Second, we detected that school track does not 
seem to play a role among foreign students in determining the likelihood of getting the BA degree. Further studies are needed, based on ad hoc surveys, to further explore the social and economic factors that influence the academic performances of foreign students that focus on second-generation immigrants.

To conclude, we note some limitations in the study that can be ascribed to the fact we are using administrative data. In assessing the importance of migratory and educational background on academic performance, we envisage two main issues: the first concerns information on the BAs' age at arrival in Italy, this influences the level of cultural and social integration attained. This, in turn, affects the academic performances. The second is related to the small size of the cohort of foreign students, which means that it was not possible to perform in-depth analysis about country-oforigin differences.

Despite these limitations, the added value of the study consists in having measured, for the first time, the academic performances of foreign students with an Italian educational background in an Italian university setting. Further studies are needed to better understand diversity within the second-generation students enrolled in Italian universities, and to highlight specific policies likely to foster equity and inclusion there. Nonetheless, our results draw attention to the urgent need for a comprehensive debate on second-generation immigrants. This starts with school policy, but raises issues of citizenship acquisition and, in particular, the role of citizenship in the integration of migrant communities.

Abbreviations

SGs: Second-generation students; ISs: International students; HS: High school; OECD: Organisation for Economic Cooperation and Development; MIUR: Ministry of Education, University and Research; RRR: Relative risk ratios; NFG: Average normalised final grade; NTD: Average normalised time-to-degree.

\section{Supplementary Information}

The online version contains supplementary material available at https://doi.org/10.1186/s41118-021-00145-3.

Additional file 1: Figure 1A. Tree plot for the normalised time-to-degree (total population)

\section{Acknowledgements}

None.

Authors' contributions

CG: conceptualisation, preparation of the dataset, methodology, writing, formal analysis; DV: conceptualisation, methodology, formal analysis, review; ET: conceptualisation, methodology, formal analysis, writing, review and editing. All authors read and approved the final manuscript.

\section{Funding}

None.

Availability of data and materials

Data that support the findings of this study are available from the Statistical Offices of Sapienza University of Rome "InfoSapienza". Restrictions apply to the availability of these data, which were used as a part of a research project.

\section{Declarations}

Competing interests

We declare no competing interests.

\section{Author details}

${ }^{1}$ Dipartimento di Metodi e Modelli per l'Economia, il Territorio e la Finanza, Sapienza Università di Roma, Rome, Italy. ${ }^{2}$ Dipartimento di Sociologia e Ricerca Sociale, Università degli Studi di Milano-Bicocca, Milan, Italy. ${ }^{3}$ Dipartimento di Scienze Statistiche, Sapienza Università di Roma, Rome, Italy. 
Received: 15 December 2020 Accepted: 15 November 2021

Published online: 20 December 2021

\section{References}

Agasisti, T., \& Salerno, C. (2007). Assessing the cost efficiency of Italian universities. Education Economics, 15(4), 455-471.

Agodini, R., \& Deke, J. (2004). The relationship between high school vocational education and dropping out. Mathematica Policy Research Inc, 8879-400.

Aiello, F., Attanasio, M., \& Priulla, A. (2020). Gli studenti stranieri negli atenei italiani: un'analisi statistica dell'ultimo decennio. Working paper, PRIN 2017HBTK5P. From high school to job placement: Micro data life course analysis of university student mobility and its impact on the Italian North-Sud divide.

Aina, C., Baici, E., \& Casalone, G. (2011). Time to degree: Students' abilities, university characteristics or something else? Evidence from Italy. Education Economics, 19(3), 311-325.

Allison, P. D. (1982). Discrete-time methods for the analysis of event histories. Sociological Methodology, 13, 61-98.

Allison, P. D. (2010). Survival analysis. In G. R. Hancock \& R. O. Mueller (Eds.), The reviewer's guide to quantitative methods in the social sciences (pp. 413-425). Routledge.

AlmaLaurea. (2018). XX Indagine. Profilo dei Laureati 2017. Retrieved May 18, 2020, from https://www.almalaurea.it/sites/ almalaurea.it/files/docs/universita/profilo/profilo2018/almalaurea_profilo_rapporto2018.pdf

AlmaLaurea. (2020). XXII Indagine. Profilo dei Laureati 2019. Retrieved May 18, 2020, from https://www.almalaurea.it/ sites/almalaurea.it/files/docs/universita/profilo/profilo2020/almalaurea_profilo_rapporto2020.pdf

Alyahyan, E., \& Düştegör, D. (2020). Predicting academic success in higher education: Literature review and best practices. International Journal of Educational Technology in Higher Education, 17(1), 1-21.

Andrade, M., \& Evans, N. (2009). International students: Strengthening a critical resource. R\&L Education.

Andrade, M. S. (2006). International students in English-speaking universities: Adjustment factors. Journal of Research in International Education, 5(2), 131-154.

Azzolini, D., Mantovani, D., \& Santagati, M. (2019). Italy: Four emerging traditions in immigrant education studies. In P. A. J. Stevens \& A. G. Dworkin (Eds.), The Palgrave handbook of race and ethnic inequalities in education (pp. 695-745). Palgrave Macmillan.

Baker, R. W., \& Siryk, B. (1999). SACQ: Student adaptation to college questionnaire: Manual. Western Psychological Services.

Bertozzi, R. (2018). University students with migrant background in Italy. Which factors affect opportunities? Italian Journal of Sociology of Education, 10(1), 23-42.

Bozzetti, A. (2018). The educational trajectories of second-generation students towards higher education: Motivations, family's role and "Institutional" bias. Italian Journal of Sociology of Education, 10(3), 82-109.

Breiman, L., Friedman, J., Stone, C. J., \& Olshen, R. A. (1984). Classification and regression trees. CRC Press.

Collins, T., \& Magnan, M. O. (2018). Post-secondary pathways among second-generation immigrant youth of Haitian origin in Quebec. Canadian Journal of Education, 41(2), 413-440.

Contini, D., \& Azzolini, D. (2016). Performance and decisions: Immigrant-native gaps in educational transitions in Italy. Journal of Applied Statistics, 43(1), 98-114.

Contini, D., Cugnata, F., \& Scagni, A. (2018). Social selection in higher education. Enrolment, dropout and timely degree attainment in Italy. Higher Education, 75(5), 785-808.

Enea, M., \& Attanasio, M. (2017). From high school to second level degree: A multi-state model to analyze the Southern University mobility in Italy. In Proceedings of the conference of the Italian Statistical Society: Statistics and data science: New challenges, new generations. Florence 28-30 June 2017.

Feliciano, C., \& Lanuza, Y. R. (2017). An immigrant paradox? Contextual attainment and intergenerational educational mobility. American Sociological Review, 82(1), 211-241.

Feliciano, C., \& Rumbaut, R. G. (2005). Gendered paths: Educational and occupational expectations and outcomes among adult children of immigrants. Ethnic and Racial Studies, 28(6), 1087-1118.

Freudenthaler, H. H., Spinath, B., \& Neubauer, A. C. (2008). Predicting school achievement in boys and girls. European Journal of Personality, 22(3), 231-245.

Furnham, A., \& Alibhai, N. (1985). Value differences in foreign students. International Journal of Intercultural Relations, 9(4), 365-375.

Garibaldi, P., Giavazzi, F., Ichino, A., \& Rettore, E. (2012). College cost and time to complete a degree: Evidence from tuition discontinuities. Review of Economics and Statistics, 94(3), 699-711.

Griga, D., \& Hadjar, A. (2014). Migrant background and higher education participation in Europe: The effect of the educational systems. European Sociological Review, 30(3), 275-286.

Heath, A., \& Brinbaum, Y. (2007). Guest editorial: Explaining ethnic inequalities in educational attainment. Ethnicities, 7(3), 291-305.

Heath, A. F., Rothon, C., \& Kilpi, E. (2008). The second generation in Western Europe: Education, unemployment, and occupational attainment. Annual Review of Sociology, 34, 211-235.

Lagomarsino, F., \& Ravecca, A. (2014). Il passo seguente.: I giovani di origine straniera all'Università. FrancoAngeli.

Mantovani, D., Gasperoni, G., \& Albertini, M. (2018). Higher education beliefs and intentions among immigrant-origin students in Italy. Ethnicities, 18(4), 603-626.

Marmolejo, F., Manley-Casimir, S., \&Vincent-Lancrin, S. (2008). Immigration and access to tertiary education: integration or marginalisation? In OECD (Ed.), Higher education to 2030: Volume 1: Demography. OECD.

Mignoli, G. P. (2012). Students' entry characteristics and academic success, AlmaLaurea working papers No. 51. Retrieved July 5, 2018, from http://www2.almalaurea.it/universita/pubblicazioni/wp/pdf/wp51.pdf

Minello, A., \& Dalla Zuanna, G. (2014). Children of immigrants in the Italian school system: What kind of assimilation? Italian Journal of Applied Statistics, 23(2), 193-213. 
MIUR. (2017). Focus_Gli immatricolati nell'aa 2016/2017 il passaggio dalla scuola all'università dei diplomati nel 2016. Retrieved October 20, 2021, from http://ustat.miur.it/media/1116/notiziario-statistico-2017-1.pdf

MIUR. (2020). Anagrafe nazionale degli studenti. Retrieved July 5, 2020, from https://anagrafe.miur.it/index.php

Murdoch, J., Guégnard, C., Koomen, M., Imdorf, C., \& Hupka-Brunner, S. (2014). Pathways to higher education in France and Switzerland: Do vocational tracks facilitate access to higher education for immigrant students? In G. Goastellec, \& F. Picard (Eds.), Higher education in societies. A multi scale perspective (pp. 149-169). Brill Sense.

Norton, L. S., \& Fatigante, M. (2018). Being international students in a large Italian university: Orientation strategies and the construction of social identity in the host context. Rassegna Di Psicologia, 35(3), 31-43.

OECD. (2019). Education at a Glance 2019: OECD Indicators. OECD Publishing. https://doi.org/10.1787/f8d7880d-en. Accessed 20 June 2020

Orupabo, J., Drange, I., \& Abrahamsen, B. (2020). Multiple frames of success: How second-generation immigrants experience educational support and belonging in higher education. Higher Education, 79(5), 921-937.

Paba, S., \& Bertozzi, R. (2017). What happens to students with a migrant background in the transition to higher education? Evidence from Italy. Rassegna Italiana Di Sociologia, 58(2), 315-352.

Ravecca, A. (2010). Immigrant children school experience: How gender influences social capital formation and fruition? Italian Journal of Sociology of Education, 2(1), 49-74.

Rienties, B., Beausaert, S., Grohnert, T., Niemantsverdriet, S., \& Kommers, P. (2012). Understanding academic performance of international students: The role of ethnicity, academic and social integration. Higher Education, 63(6), 685-700,

Rumbaut, R. G. (1997). Ties that bind: Immigration and immigrant families in the United States. In A. Booth, A. C. Crouter, \& N. S. Landale (Eds.), International migration and family change (pp. 3-46). Lawrence Earlbaum.

Sherry, M., Thomas, P., \& Chui, W. H. (2010). International students: A vulnerable student population. Higher Education, 60(1), 33-46.

Smith, R. A., \& Khawaja, N. G. (2011). A review of the acculturation experiences of international students. International Journal of Intercultural Relations, 35(6), 699-713.

Vergolini, L., \& Vlach, E. (2017). Family background and educational path of Italian graduates. Higher Education, 73(2), 245-259.

\section{Publisher's Note}

Springer Nature remains neutral with regard to jurisdictional claims in published maps and institutional affiliations.

\section{Submit your manuscript to a SpringerOpen ${ }^{\circ}$ journal and benefit from:}

- Convenient online submission

- Rigorous peer review

- Open access: articles freely available online

- High visibility within the field

- Retaining the copyright to your article

Submit your next manuscript at $\boldsymbol{\nabla}$ springeropen.com 